\title{
Frequency of moles in a defined population
}

\author{
K R COOKE, G F S SPEARS, AND D C G SKEGG
}

From the Department of Preventive and Social Medicine, University of Otago Medical School, Dunedin, New Zealand

SUMMARY The occurrence of moles was studied in a community survey of 872 adults, using criteria that allowed comparison with two earlier surveys. Men and women had similar numbers of moles-on average, 15 moles of diameter $2 \mathrm{~mm}$ or greater, and 39 moles of all sizes. The frequency of moles declined with age and varied according to body site. Comparison of the findings with those of previous surveys - in New York in about 1950 and in Sydney in about 1970-suggested that the frequency of moles has increased as malignant melanoma has become more common. Little is known about the epidemiology of moles, which may hold the key to the explanation of the rising incidence of melanoma in many countries.

Malignant melanoma is becoming more common in many developed countries. ${ }^{1}$ The aetiology of this disease is obscure, although solar radiation is almost certainly involved. ${ }^{2}$ In Australia and New Zealand, at least two-thirds of patients state that their melanomas arose from pre-existing moles. ${ }^{34}$ If pigmented naevi (moles) can be precursor lesions for malignant melanoma, the rising incidence of melanoma could be due either to an increasing frequency of moles or to an increasing tendency for moles to become malignant (or to a combination of these changes). If the first change is involved, there should be an association between the prevalence of moles and the incidence of malignant melanoma.

Only two detailed surveys of moles in Caucasian adults have been reported, and their results cannot be compared because different criteria were used. ${ }^{56} \mathrm{We}$ therefore determined the frequency of pigmented naevi in a defined population, choosing criteria for counting that would enable us to compare our results with data from each of the earlier surveys.

\section{Methods}

In the winter of $1981,78 \%$ of the adult population of the small country town of Milton (Otago, New Zealand) participated in the third Milton Health Survey. ${ }^{7}$ During this survey, all people under the age of 70 years were examined, and the distribution and frequency of their pigmented naevi (moles) were recorded. This report is concerned with all
non-Maoris aged 20-69 years. The non-Maor population of Milton is almost exclusively European in origin.

An indication of the response in different sex and age groups was obtained by comparing the number of people counted for moles (excluding Maoris) wit the numbers of non-Maori people in the Borough of Milton at the quinquennial census, which was held two months before the mole counts (Table 1). ${ }^{89}$ The census populations may have included a number of visitors to the Borough whereas the mole counts are restricted to residents of the Borough. These estimates of the response rates for individual sex and age groups ranged from 63 to $99 \%$.

Participants undressed to their underpants and (in women) their brassiere and were examined by one of seven trained counters (KRC and six senior medical students who had received additional training). To maintain co-operation, the anterior chest of women

Table 1 Estimated response rates

\begin{tabular}{|c|c|c|}
\hline \multirow{2}{*}{$\begin{array}{l}\text { Age } \\
\text { (years) }\end{array}$} & \multicolumn{2}{|c|}{ Percentage of census population (non-Maoris) } \\
\hline & Males & Females \\
\hline $20-29$ & 68 & 67 \\
\hline $30-39$ & 84 & 85 \\
\hline $40-49$ & 99 & 75 \\
\hline $50-59$ & 68 & 79 \\
\hline $60-69$ & 69 & 63 \\
\hline $20-69$ & 76 & 73 \\
\hline
\end{tabular}


and the abdomen and buttocks of all subjects were not examined. To allow direct comparisons between sexes, the reported values also exclude moles on the anterior chest in men. The back and arms were first inspected to determine the pattern of freckling, and to detect lentigines and seborrhoeic keratoses. Freckles, lentigines, and any arrays of similarly and uniformly pigmented macules were excluded. If the counter was in any doubt as to whether a particular skin blemish was of melanocytic origin it was excluded. One or both of two types of count were carried out.

On all participants, moles that were greater than or equal to $2 \mathrm{~mm}$ in apparent diameter were counted. This size limit was chosen to allow comparison with Nicholls' earlier survey. ${ }^{6}$ Duplicate counts on the upper limbs and back, carried out without warning to the first counter and without knowledge of the initial count, showed a high degree of correlation $(r=0 \cdot 81$, $45 \mathrm{df}, \mathrm{p}<0.001)$. In addition to this restricted count, all moles were counted on the one-fifth of participants seen in the last three days of the survey. This more complete count included pigmented naevi that were smaller than the size limit applied in the first count, and also included some naevi that the counter considered to be moles but that would have been excluded from the restricted count because of a minor degree of diagnostic uncertainty. Counts duplicated again showed a high degree of correlation $(\mathrm{r}=0.89,12 \mathrm{df}, \mathrm{p}<0 \cdot 001)$.

There was no evidence in any of the duplicate counts that a counter had included an inappropriate skin mark as a pigmented naevus. Most of the skin lesions counted appeared to be acquired naevi of junctional or compound form. Counts were recorded by body site in a number of descriptive categories based on elevation, size, and pigmentation. The diagnosis of flat, brown or tan moles provided the most difficult problem. Such diagnoses were validated by an external review of 300 photographs of these moles from randomly selected subjects. The photographs were assessed by two independent and experienced observers (Dr David E Elder, Pigmented Lesion Group, Philadelphia and Dr Mark H Greene, NCI, Bethesda); $96 \%$ of the diagnoses were confirmed by either both $(92 \%)$ or one $(4 \%)$ of the reviewers.

\section{Results}

The 872 people studied included 436 men and 436 women, all of whom were counted for moles $\geqslant 2 \mathrm{~mm}$ in diameter; 105 men and 73 women also had the unrestricted count (Table 2). For each counting procedure, low counts were recorded most often. For example, among 20-29 year old men counted for moles $\geqslant 2 \mathrm{~mm}, 49$ had fewer than 10 moles, 33 had $10-19,13$ had $20-29,7$ had $30-39$, and 13 had 40 or more, of whom 2 had 70 or more; only three were recorded as having no moles, one of whom was known to have a mole on the chest.

Table 2 shows the mean number of moles, according to sex and age. Both men and women had an average of 14-15 moles of diameter greater than or equal to $2 \mathrm{~mm}$, and 38-39 moles of all sizes. Although there were no consistent differences between the sexes, the frequency of moles declined significantly with age (for moles $\geqslant 2 \mathrm{~mm}, \mathrm{r}=-0 \cdot 14$, $\mathrm{df}=870, \mathrm{p}<0.001)$.

Table 2 Mean number of moles in New Zealand adults*

\begin{tabular}{|c|c|c|c|c|}
\hline \multirow{2}{*}{$\begin{array}{l}\text { Age } \\
\text { (years) }\end{array}$} & \multicolumn{2}{|c|}{$\begin{array}{l}\text { Mean number of moles } \\
\geqslant 2 \mathrm{~mm}^{\dagger}\end{array}$} & \multicolumn{2}{|c|}{$\begin{array}{l}\text { Mean number of moles } \\
\text { of all sizes }\end{array}$} \\
\hline & Males & Females & Males & Females \\
\hline $20-29$ & $17(115)$ & $16(108)$ & $47 \quad(29)$ & 53 (22) \\
\hline $30-39$ & $17(113)$ & $16(107)$ & 43 (26) & 52 (16) \\
\hline $40-49$ & $13(83)$ & $16(74)$ & 28 (24) & 24 (15) \\
\hline $50-59$ & 11 (75) & $13(85)$ & 27 (18) & 26 (15) \\
\hline $60-69$ & $14(50)$ & $9(62)$ & $48 \quad(8)$ & 21 (5) \\
\hline $20-69$ & $15(436)$ & $14(436)$ & $38(105)$ & 39 (73) \\
\hline
\end{tabular}

* Moles on the anterior chest, abdomen, and buttocks are not included. tNumbers of subjects shown in parentheses.

Similarly, mole counts at individual body sites were generally lower for participants aged 40-69 years than for those aged 20-39 (Table 3). As many more people were counted for moles $\geqslant 2 \mathrm{~mm}$ than for all moles, sites for the latter have been aggregated into larger groups, which approximate those used by Pack et $a l .{ }^{5}$ When counts for individual body sites were compared, there were differences between the sexes. Women had more moles on the upper limbs, face and neck, while men had more moles on the back. On the lower limbs men and women had similar numbers of moles. The distribution of moles, by site, differed slightly depending on the counting method, possibly reflecting different balances between larger and smaller moles in different regions of the body. Generally, the upper and lower limbs had similar numbers of moles and the highest mean counts among the sites. The mole counts for the backs of men were also high, particularly for moles $\geqslant 2 \mathrm{~mm}$.

COMPARISONS WITH PREVIOUS SURVEYS

In Table 4 the results of this study are presented in a form that allows comparison with two previous surveys-in New York in about $1950^{5}$ and in Sydney in about 1970.6 Our restricted count can be compared with data from the survey in Sydney by Nicholls, ${ }^{6}$ who also confined attention to moles $2 \mathrm{~mm}$ or larger in diameter. The figures derived from Nicholls' paper relate to the areas of the body that we 
Table 3 Mole counts according to body site

\begin{tabular}{|c|c|c|c|c|c|c|}
\hline \multirow[b]{2}{*}{ Site } & \multirow[b]{2}{*}{ Sex } & \multicolumn{2}{|c|}{$\begin{array}{l}\text { Mean number of } \\
\text { moles } \geqslant 2 \mathrm{~mm}\end{array}$} & \multirow[b]{2}{*}{ Sex } & \multicolumn{2}{|c|}{$\begin{array}{l}\text { Mean number of } \\
\text { moles }\end{array}$} \\
\hline & & $\begin{array}{l}20-39 \\
\text { years }\end{array}$ & $\begin{array}{l}40-69 \\
\text { years }\end{array}$ & & $\begin{array}{l}20-39 \\
\text { years }\end{array}$ & $\begin{array}{l}40-69 \\
\text { years }\end{array}$ \\
\hline $\begin{array}{l}\text { Upper limbs } \\
\text { right } \\
\text { left }\end{array}$ & $\begin{array}{l}\mathbf{M} \\
\mathbf{F} \\
\mathbf{M} \\
\mathbf{F}\end{array}$ & $\begin{array}{l}1 \cdot 8 \\
3 \cdot 0 \\
2 \cdot 2 \\
3 \cdot 3\end{array}$ & $\left.\begin{array}{l}1 \cdot 4 \\
2 \cdot 0 \\
1 \cdot 3 \\
2 \cdot 1\end{array}\right\}$ & $\begin{array}{l}\mathbf{M} \\
\mathbf{F}\end{array}$ & $\begin{array}{l}13 \\
23\end{array}$ & $\begin{array}{l}8 \\
9\end{array}$ \\
\hline $\begin{array}{l}\text { Face } \\
\text { Neck }\end{array}$ & $\begin{array}{l}\mathbf{M} \\
\mathbf{F} \\
\mathbf{M} \\
\mathbf{F}\end{array}$ & $\begin{array}{l}0.6 \\
1.0 \\
0 \cdot 8 \\
1 \cdot 3\end{array}$ & $\left.\begin{array}{l}0.5 \\
0.8 \\
0.5 \\
1.2\end{array}\right\}$ & $\begin{array}{l}\mathbf{M} \\
\mathbf{F}\end{array}$ & $\begin{array}{l}3 \\
6\end{array}$ & $\begin{array}{l}2 \\
3\end{array}$ \\
\hline Back & $\stackrel{\mathbf{M}}{\mathrm{F}}$ & $\begin{array}{l}5 \cdot 1 \\
2 \cdot 4\end{array}$ & $\begin{array}{l}4 \cdot 1 \\
1.9\end{array}$ & $\begin{array}{l}\mathbf{M} \\
\mathbf{F}\end{array}$ & $\begin{array}{r}11 \\
6\end{array}$ & $\begin{array}{l}8 \\
2\end{array}$ \\
\hline $\begin{array}{l}\text { Lower limbs } \\
\text { right } \\
\text { left }\end{array}$ & $\begin{array}{l}\mathbf{M} \\
\mathbf{F} \\
\mathbf{M} \\
\mathbf{F}\end{array}$ & $\begin{array}{l}3 \cdot 4 \\
2 \cdot 5 \\
3 \cdot 4 \\
2 \cdot 2\end{array}$ & $\left.\begin{array}{l}2 \cdot 3 \\
2 \cdot 5 \\
2 \cdot 5 \\
2 \cdot 7\end{array}\right\}$ & $\stackrel{\mathbf{M}}{\mathbf{F}}$ & $\begin{array}{l}18 \\
18\end{array}$ & $\begin{array}{l}13 \\
11\end{array}$ \\
\hline
\end{tabular}

studied, and the data have been standardised for age. In the New York survey of Pack et al ${ }^{5}$ all moles were counted: their figure for white adults (14.6 moles per person) has been adjusted to allow for our omission of certain body areas. Since Pack $e \mathrm{al}^{5}$ did not specify their results by sex or age, other standardisation is not possible. Table 4 also shows estimates of the incidence of malignant melanoma corresponding to the three surveys. The frequency of moles has increased as melanoma has become more common.

The results of our study can also be compared with those of Nicholls ${ }^{6}$ for 75 combinations of sex, decade of age, and body area; the New Zealand frequencies were generally higher than those recorded in Sydney in about 1970.

Table 4 Comparison with previous surveys

\begin{tabular}{lcccc}
\hline & \multicolumn{3}{l}{$\begin{array}{l}\text { Mean number ofmoles in comparable } \\
\text { body areas }\end{array}$} \\
\cline { 3 - 5 } $\begin{array}{l}\text { Place and time } \\
\text { of survey }\end{array}$ & $\begin{array}{l}\text { Incidence of malignant } \\
\text { melanoma per } 100000^{*}\end{array}$ & $\begin{array}{l}\text { Diameter } \geqslant 2 \mathrm{~mm} \\
\text { Males }\end{array}$ & $\begin{array}{l}\text { All sizes } \\
\text { (both sexes) }\end{array}$ \\
\hline $\begin{array}{l}\text { New York } \\
\text { c } 1950\end{array}$ & 2 & - & - & $12 \ddagger$ \\
$\begin{array}{l}\text { Sydney } \\
\text { c } 1970\end{array}$ & 11 & 9 & 12 & - \\
$\begin{array}{l}\text { New Zealand } \\
1981\end{array}$ & 15 & $15 \dagger$ & $14 \dagger$ & 39 \\
\hline
\end{tabular}

*The sources of these estimates, which are standardised for age using a world standard population, are given in the discussion.

+Directly standardised to the age distribution in the Sydney survey.

¥Adjusted for omission of certain body areas, using data on site distribution from the paper by Pack et al. . $^{\text {. }}$

\section{Discussion}

Enumeration of moles in a community survey of Caucasian adults showed a higher frequency than in two studies carried out in the past. Although only three-quarters of the eligible population took part in the Milton Health Survey, it is very unlikely that participants were self selected in relation to numbers of moles. The survey was primarily concerned with cardiovascular disease, and fear of venesection was the reason most often given for non-participation. The mole count appeared to be regarded by the townsfolk as a source of amusement: the local general practitioner and district nurse did not notice any concern about moles before or after the survey.

Mole surveys are difficult epidemiological tasks. The size limit of $2 \mathrm{~mm}$ which we used to permit comparison with an earlier survey ${ }^{6}$ was not a natural cut-off point, and it was difficult to develop precise diagnostic criteria because of the variety of appearances of melanocytic naevi. ${ }^{10}{ }^{11}$ Although the training of counters emphasised the clinical features of seborrhoeic keratoses, it is likely that a few of these would have been counted. Nevertheless, the diagnosis of most of the common acquired junctional and compound naevi was straightforward, and in an attempt to ensure that any systematic bias was in the direction of a low count, we adopted a conservative approach by frequently reminding counters of the rule: "If in doubt-leave it out." This approach $\mathbb{\mathbb { D }}$ together with the exclusion of all lesions that could be freckles or lentigines would undoubtedly have led to a number of brown junctional naevi being excluded from the count.

Early attempts to study the occurrence of moles were discussed by Lewis. ${ }^{12}$ The surveys with which our results can be compared were carried out in about 1950 in New York and in about 1970 in Sydney. There are a number of points on which the studies can be compared. In Pack's New York study, men and women also had similar aggregate numbers of moles. ${ }^{13}$ In the Sydney study women had slightly more moles than men, but sampling was not systematic. ${ }^{6}$ Our observation that mole frequency declined with age was expected from reports of clinical experience and histopathological and clinical surveys of selected groups. ${ }^{6101114}$ The site distribution of moles in Milton was similar to that of the surveys by Pack and Nicholls in that moles were particularly common on both the upper and the lower limbs. There is thus some consistency in the data collected in these three surveys.

In the American study, Pack et al ${ }^{5}$ examined 1000 adult white outpatients who were attending hospital for unrelated complaints. Although the results were not specified by age, the difference in the aggregate count from our survey (Table 4) was too great to be due to differences in the age distributions of the populations studied. Moreover the frequencies of moles at particular body sites were consistently 
higher in our survey. In Sydney, Nicholls ${ }^{6}$ counted moles on 1528 people, of whom a large proportion were children. His criteria for inclusion depended on alterations to the surface marking overlying a pigmented skin mark; these criteria were applied in a way that would have included practically all moles (personal communication from Dr E M Nicholls). Again the New Zealand survey revealed a higher frequency of moles.

The age standardised incidence of malignant melanoma corresponding to these surveys was 2 per 100000 for the American study (calculated from rates from the Connecticut Tumor Registry $1950-54^{15}$ ) and 11 per 100000 for New South Wales in 1970-71. ${ }^{16}$ As data on the incidence of melanoma in 1981 in the region of New Zealand around Milton will not be available for several years, we estimated the incidence of 15 per 100000 from the trend in New Zealand non-Maori incidence rates from 1948 to $1977,{ }^{17}$ allowing for the lower rate observed in this most southerly region of New Zealand. ${ }^{4}$ Thus, of the three surveys, the New Zealand survey corresponded to the population with the highest melanoma incidence, and the group studied by Pack et al came from the population with the lowest melanoma incidence.

The results of this study suggest that the prevalence of moles has increased as malignant melanoma has become more common. This conclusion needs to be confirmed, since it is based on the observations of three groups of workers studying populations separated by space as well as time. It is, however, supported by several small studies of special groups of Caucasians in which the numbers of moles per person ranged from 6,13 , and 17 in the relatively low incidence areas of France, Philadelphia, and Glasgow (young adults), respectively, to a value of 40 reported by Lane-Brown recently for control observations in Australia.$^{18-21}$ Thus it seems possible that there is a relation between the occurrence of moles in a community and the incidence of malignant melanoma.

Several other observations point to the importance of moles in the development of melanoma. First, as mentioned previously, a majority of patients say that their melanomas arose from pre-existing moles. ${ }^{34}$ Although histological confirmation of this will be difficult if the naevus has been destroyed by the tumour, a pre-existing naevus was found in $53 \%$ of a series of very early melanomas. Recently, a syndrome of familial malignant melanoma has been shown to involve the occurrence of unusual 'dysplastic naevi' ${ }^{23}$ Finally, preliminary results from recent case control studies suggest that individuals with many moles, or with large moles, may have an elevated risk of malignant melanoma. ${ }^{24} 25$
The secular increases in melanoma incidence and mortality in New Zealand and other countries are consistent with a birth cohort-dependent change in an important aetiological factor. ${ }^{17}$ If the increasing melanoma rates were secondary to changes in the frequency of moles, this could explain the birth cohort effect, as the tendency to develop moles is most evident in the first few decades of life..$^{11}$

Considering that moles are the most accessible of all the possible precursor lesions for human cancer, it is remarkable how little is known about their epidemiology. Further research is needed to discover what determines the number of moles on a person and whether, apart from familial syndromes, particular types of mole carry a higher risk of malignancy.

This work was supported by the Medical Research Council and the National Heart Foundation of New Zealand. We are particularly grateful to Professor F O Simpson (Director of the Milton Health Survey) and to the people, and Rotary Club, of Milton. We are grateful to Dr B D Turnbull and Dr H C W Stringer for dermatological advice, and to Dr David E Elder and Dr Mark H Greene for their external validation of the photographs.

\section{References}

${ }^{1}$ Lee JAH. Melanoma. In: Schottenfeld D, Fraumeni JF Jr, eds. Cancer epidemiology and prevention. Philadelphia: WB Saunders, 1982: 984-95.

${ }^{2}$ Anonymous. The aetiology of melanoma (Editorial). Lancet. 1981 ; i: 253-5.

${ }^{3}$ Milton GW. The diagnosis of malignant melanoma. In: McCarthy WH, ed. Melanoma and skin cancer. Sydney: Government Printer, 1972: 163-74.

${ }^{4}$ Scott JP, Jolly KD, MacKinnon MJ, Clark AM. Melanoma in Otago and Southland. NZ Med J 1980; 92: 422-4.

${ }^{5}$ Pack GT, Lenson N, Gerber DM. Regional Distribution of moles and melanomas. Arch Surg 1952; 65: 862-70.

${ }^{6}$ Nicholls EM. Development and elimination of pigmented moles, and the anatomical distribution of primary malignant melanoma. Cancer 1973; 32: 191-5.

${ }^{7}$ Simpson FD, Paulin JM, Phelan EL, et al. Further surveys in Milton, 1978 and 1981: blood pressure, height, weight and 24-hour excretion of sodium and potassium. NZ Med J 1982; 95: 873-6.

${ }^{8}$ Department of Statistics. Ages, marital status and fertility. (New Zealand census of population and dwellings 1981, Vol. 2.) Wellington, NZ: Department of Statistics, 1982.

${ }^{9}$ Department of Statistics. Maori population and dwellings. (New Zealand census of population and dwellings 1981, Vol. 8A) Wellington, NZ: Department of Statistics, 1983.

${ }^{10}$ Mackie RM. Melanocytic naevi. In: Rook A, Wilkinson DS, Ebling FJG, eds. Textbook of dermatology. Oxford: Blackwell, 1979: vol. 1: 173-83. 
${ }^{11}$ Becker SW Jr. Pigmented nevi. In: Demis DJ, Dobson RL, McGuire J, eds. Clinical dermatology. Hagerstown: Harper \& Row, 1976: (unit) 11-47.

${ }^{12}$ Lewis CWD. Melanoma and melanosis. Ann R Coll Surg Engl 1956; 19: 165-84.

${ }^{13}$ Pack GT, Davis J. The pigmented mole. Postgrad Med 1960; 27: 270-82.

${ }^{14}$ Stegmaier OC. Natural regression of the melanocytic nevus. J Invest Dermatol 1959; 32: 413-21.

${ }^{15}$ Foote FM. Cancer in Connecticut: incidence and rates 1935-1962. Hartford, Connecticut: Connecticut Tumor Registry, 1966.

${ }^{16}$ McCarthy WH, Black AL, Milton GW. Melanoma in New South Wales: an epidemiological survey 1970-76. Cancer 1980; 46: 427-32.

${ }^{17}$ Cooke KR, Skegg DCG, Fraser J. Trends in malignant melanoma in New Zealand. Int $J$ Cancer 1983; 31: 715-8.

${ }^{18}$ Cesarini JP. Epidémiologie des mélanomes malins et des autres cancers de la peau. Rev Médecine 1979; 20: 1451-2.

${ }^{19}$ Elder DE. Nonfamilial precursors to melanoma. Proc NIH Consensus Development Conference on Precursors to Malignant Melanoma 1983; 21-6.
${ }^{20}$ Mackie RM. Multiple melanoma and atypical melanocytic naevi-evidence of an activated and expanded melanocytic system. Br J Dermatol 1982; 107: 621-9.

${ }^{21}$ Lane-Brown $M$. Non-melanoma skin cancer; dermato-heliosis and the "Celts of Australia." Proc Clin Oncol Soc Austr 1982; 10.

${ }^{22}$ Sagebiel RW. Histopathology of borderline and early malignant melanomas. Am J Surg Pathol 1979; 3: 543-52.

${ }^{23}$ Clark WH Jr, Reimer RR, Greene MH, Ainsworth AM, Mastrangelo MJ. Origin of familial malignant melanomas from heritable melanocytic lesions. "The B-K mole syndrome." Arch Dermatol 1978; 114: 732-8.

${ }^{24}$ Reynolds P, Austin D, Thomas J. Familial and occupational risks associated with malignant melanoma of the skin. Am J Epidemiol 1982; 116: 570.

${ }^{25}$ Rhodes AR, Sober AJ, Mihm MC. Possible risk factors for primary cutaneous malignant melanoma. Clin Res 1980; 28: 252A. 